\title{
Study on Measures for Development of Continuing Education Based on Social Stratification
}

\author{
Jichuan Li \\ Linyi University \\ Linyi, China 273400
}

\begin{abstract}
Based on the classification of occupations, the social stratification in China, which is weighed through organizational resources, economic resources and cultural resources, brings opportunities and spaces for the continuing education in the country, to explore measures for the development of the continuing education under the background of new social stratification and find a way to promote the continuing education will play a significant role in the comprehensive development of education in the country.
\end{abstract}

Keywords—social stratification; continuing education; measures

\section{INTRODUCTION}

Going with the establishment and development of social market economy system, in the late 1990, a broken and fragmented social structure came into being in China, the drastic social changes have created a new society, new social groups or social stratifications have appeared. The groups or stratifications have different appeals for education, which brings important impacts on the education especially the continuing higher education in the country, therefore, under the background of social stratification, to research ways for the development of continuing education will play an instructive role in advancing the continuing education and improving the education quality.

\section{SOCIAL STRATIFICATION IN THE STAGE OF TRANSFORMATION}

As far as the social stratification, currently typical theories mainly include Marxist class and stratum theory and Max Weber's stratification theory, the former stressed the position of the people in relations of production, which is based on the production goods occupied; the latter stressed fortune, reputation and power, which is based on economic status, social status and political status. Most of the west sociology researchers study the social stratification on the basis of Weber's theory for example, Mills classified white collar, blue collar and so on, Warner et al stated six stratums of diversity. In the west researches on social stratification, it is mainly based on measured value of occupational reputations. For example, Parsons thought occupation is the

Shandong Social Sciences Layout and Research Project Staged Results of "Research on Integration of County-based Rural Vocational Education and Adult Education under the Background of Agricultural Modernization" (Project Approval No: 14CJYJ07 ). most important base for the social stratification in the US, both fortune and reputation depend on it, and the occupational grades stand for individual achievements, which is an affirmation and reward for the individual achievements by the society. Therefore, according to specific and fine differences of the people in occupational labor, pay and reputation, he divided social members into multiple stratums arranged continuously, forming a continued spectrum.

In recent years, among studies of social structure changes and social stratification, some scholars raise a theoretical framework "Based on the classification of occupations, the social stratification is weighed through organizational resources, economic resources and cultural resources". Organizational resources consists of administrative organizational resources and political organizational resources, it refers to the abilities of state power organs and the Party organization system to control social resources (including HR and materials); economic resources mainly refer to the ownership, use right and operation right on production goods; Cultural (technical) resources refer to the knowledge and skills owned that are acknowledged by certificates or qualification. Based on occupational classification, Prof. Lu Xueyi with Chinese Academy of Social Sciences, divides Chinese economic and social stratums into ten stratums and five social and economic status, which is weighed by organizational resources, economic resources and cultural resources. The ten stratums include state and social management, managers, private entrepreneurs, professional and technicians, office workers, individual industrial and commercial business, business service workers, industrial workers, agricultural laborers, the unemployed, jobless and semi-employed. Five social and economic classes include: upper class, middle- upper class, middle -middle class, middle-lower class and underclass. This classification standard provides basis for us to examine the relationship between continuing higher education and social stratification. Different stratums or different economic grades have different requirements on the continuing education due to economic status and social status, and the social stratification determines the form of continuing education, and the continuing education changes and consolidate to some degree the social stratification. The above theories are basic foothold and starting point for this article. 


\section{MEASURES FOR THE CONTINUING EDUCATION UNDER THE BACKGROUND OF SOCIAL STRATIFICATION}

\section{A. Set A Concept of Grand Continuing Education under the Permanent Educational Framework}

The continuing education is a important of educational undertaking in China and a main way for education to serve the construction of socialist modernization and an energetic new educational system for traditional education going toward life long education. Outline of National Mediumand Long-Term Program for Education Reform and Development points out: "Continuing education is an educational activity offered to all social members after school education, especially the continuing education activities are a major part of life-long study system." "With the participation of continuing education increased, the proportion of workers who participate in the continuing education reaches 50\%". Nowadays, with the national educational system perfected day by day, a life-long educational system has come into being, and all the people are encouraged to learn what the need, succeed in what they learn, use what they have had". Influenced by the concept of life long education, the people of each class will offer a permanent, potential and broad development space for the continuing education. Therefore, the educational institutions which carry out the continuing education shall improve the recognition under the concept of grand education, create conditions to the maximum, set up and build a complete system which provide life long education for participants and erect a flyover for the life long learning while establishing development layouts for the continuing education. Within the life long educational system where external development is combined with internal development, the continuing education shall be open to the public as much as possible, realizing the connection with other kinds or levels of education, for integrated development via penetration. It needs to adjust the simplicity, changing from "certificate compensation" gradually to cultivate the people's awareness and abilities in getting, using and creating knowledge so as to improve professional skills and accomplishment of all classes, adapt to the requirements of market economy to different talents, and all social classes will get how to learn and capable of life long learning.

\section{B. Stand on the Degree Education and Strive to Develop the Non-Degree Education}

To develop the degree-based continuing education steadily and strive to develop the non-degree continuing education is the direction that the Outline of National Medium-and Long-Term Program for Education Reform and Development raises for the development of continuing education according to the needs of all social stratums. In the current stage even up to a long time period in the future, the degree education is still a key part of the continuing education.

In 2010, the students admitted to colleges and universities totaled 6.57 million, of whom, 3.39 million were undergraduates, 3.18 million were higher vocational education students (technical colleges) occupying $48.4 \%$ of the total. Going with the development of higher education in the country, though the proportion of undergraduate and technical college students have changed, yet, according to the requirements of economic development, the proportion will not change severely. In accordance with the Outline of National Medium-and Long-Term Program for Education Reform and Development, in 2015, the students of higher education totaled 30.8 million, which will reach 33 million in 2020. Suppose the proportion between undergraduate and technical college students is $45 \%$, the students of vocational higher education (technical college) will reach 13.86 million and 14.85 million respectively in 2015 and 2020. After graduation, a great number of students of vocational higher education (technical colleges), being middle-lower classes, have stronger desire to improve their degree to undergraduate in order to improve their social status or career renewal, besides, though the gross enrolment rate is increased year by year in the country, there are still a lot of middle school students who are not admitted to colleges, most of them become the lower classes as industrial workers, farmers or the employed or semi-employed in urban and rural areas, most of them expect to change their fates through degree (technical colleges or undergraduate), therefore, the continuing education in the country must be based on the degree education and developing steadily.

Degree education and non-education advance together, promote and promote each other. The story of the continuing education in the country turns out that the development positioning of continuing education shall vary with the social needs in different stages. When the size of continuing education increased fivefold in the country, possibly the positioning of continuing education needs to shift to the life long education for the employed, seen from the development trend of continuing education and requirements of life long education, non-degree education such as post training, qualification training and continuing education will become a necessary appeal of the people at the social middle-middle class, middle-lower class and underclass. In the current stage, the degree education in the continuing education is fully developed in the country, yet the non-degree education develops in imbalance. With the rapid economic growth in the country and the continuous adjustment of industrial structure, it will be a must to rapidly push the continuing vocational education and training, and the situation of labor in the future impersonally forms a large need of employment training. Estimations show, laborer aged 15-59: 810 million in 2000, 926-961 million in 2010, of who those who received post-second education in urban areas occupied about 5\%, those who received no continuing professional training occupied about $4.5 \%$. In a word, the continuing education may start with vocational training, and develop on the basis of steady continuing degree education.

\section{Introduce the Continuing Education to Communities, Set up Community Colleges and Further Widen Channels of Continuing Education}

A community is a relatively independent society where homogeneous people live in a region with certain social relations and connections, it consists of people, area, service 
facilities and sense of identity held by members, it is divided into rural communities and urban communities, owning functions such as living, amusement, belonging and development. China is always in a strict administration, which reaches grassroots, yet with the legalized administration in the modern society, social economic development takes on regional characteristics, some public social managements gradually enter regions, grassroots, communities and parks, which reach out to the social life the people, and regional management has become a management mode for the society. With the gradual improvement of community functions, the conditions for continuing education to enter communities have been mature increasingly, and it has been a necessity for the combination of communities and continuing education.

In Apr 2000, the Ministry of Education issued Notice to Carry out Education Test in Some Regions, making arrangement for the community education test, and the community education test areas were selected in 8 large and medium cities such as Chaoyang District, Beijing, Hexi District, Tianjin and so on. At present, 110 community education test areas have been set up in more than half of provinces, autonomous regions and municipalities with independent planning status in the country, of which, the typical areas include Chaoyang Community College, Beijing, Nanshi Community College, Shanghai, Zhabei Community College and so on. Through integrating community education resources, the community colleges meet the needs of education of members to some degree, improving their cultural accomplishment and professional skills and strengthening the social senses of belongings and community cohesion so as to push the community development. And the community college-based continuing education shall be further carried out in large and medium cities in the country.

In the face of the rapid development of rural economy and education, it has been mature to set up community education colleges in rural areas so as to meet the needs of building new villages. The community education colleges in rural areas may carry out flexible policies in enrollment, training and completion, executing credit systems and flexible schooling systems, issuing completion certificate, vocational qualification certification, green certificates and so on so as to facilitate the students in systems in multiple forms according to the needs of the students. For example, according to the requirements of different regions and work fields in international and domestic labor markets, urban, developed areas and rural construction, adjust the training project structure, create new training projects in a great need by the society, set new courses reflecting new technique, process and standards, increase elective courses to teach startup knowledge and strengthen the startup abilities. Establish cooperation with rural enterprises, carry out the directed education, farmer skill training, and international trainees and so on, set up an integrated cultivation mode combining enrollment and employment, attracting students by employment and promoting the development of rural community colleges by students.

\section{CONCLUSION}

In a word, the continuing education may greatly improve the labor quality and skills of laborers from all classes and meet the needs of the community members for survival, and it plays a crucial role in helping community members set ideals, purify morality, cultivate values and characters, enrich healthy cultural art, sports amusement education, living skills education, amusement education and the like, and develop the community members in all aspects such as physiology, psychology, knowledge, skill, spiritual drive and creativity and achieve a harmonious progress in intelligence, physical power, interest and sociality.

\section{REFERENCES}

[1] Meng Chunqing, Zhang Shanmin, On Educational Fairness unde Social Stratification (Fujian Tribune (A Economics \& Sociology Monthly)), 2009 (6).

[2] Wang Hongcai, Development of Adult Higher Education: Independence, Affiliation and Transformation, Research in Educational Development, 2010(13/14)

[3] Lu Xiaozhu, Lu Ningning, Difficulty and Solution Thoughts of Adult Higher Education, Higher Education Forum, 2009(11).

[4] Lyu Guanxin, Featured Development of Adult Higher Education Colleges: Selection and Surpass of Higher Education Marketization, Journal of Zhejiang Normal University (Social Sciences, 2010(2). 